\title{
Pleural abnormalities in COVID-19: a narrative review
}

\author{
Biplab K. Saha ${ }^{1}$, Woon H. Chong ${ }^{2}$, Adam Austin ${ }^{3}$, Ritu Kathuria ${ }^{4}$, Praveen Datar ${ }^{1}$, Boris Shkolnik ${ }^{2}$, \\ Scott Beegle , Amit Chopra $^{2}$
}

${ }^{1}$ Department of Pulmonary and Critical Care Medicine, Ozarks Medical Center, West Plains, MO, USA; ${ }^{2}$ Department of Pulmonary and Critical Care Medicine, Albany Medical Center, Albany, NY, USA; ${ }^{3}$ Department of Pulmonary and Critical Care Medicine, University of Florida, Gainesville, FL, USA; ${ }^{4}$ Department of Infectious Disease, Ozarks Medical Center, West Plains, MO, USA

Contributions: (I) Conception and design: BK Saha, WH Chong, A Austin, P Datar; (II) Administrative support: B Shkolnik, S Beegle, A Chopra; (III) Provision of study materials or patients: None; (IV) Collection and assembly of data: BK Saha, WH Chong, A Austin, R Kathuria; (V) Data analysis and interpretation: BK Saha, WH Chong, P Datar; (VI) Manuscript writing: All authors; (VII) Final approval of manuscript: All authors.

Correspondence to: Biplab K. Saha, MD. Ozarks Medical Center, 1100 Kentucky Avenue, West Plains, MO 65775, USA. Email: spanophiliac@yahoo.com.

Objective: This narrative review aims to provide a detailed overview of pleural abnormalities in patients with coronavirus disease 19 or COVID-19.

Background: Severe acute respiratory syndrome coronavirus 2 (SARS-Cov-2) is a novel beta coronavirus responsible for COVID-19. Although pulmonary parenchymal and vascular changes associated with COVID-19 are well established, pleural space abnormalities have not been the primary focus of investigations.

Methods: Narrative overview of the medical literature regarding pleural space abnormalities in COVID-19. The appropriate manuscripts were identified by searching electronic medical databases and by hand searching the bibliography of the identified papers. Pleural abnormalities on transverse and ultrasound imaging are discussed. The incidence, clinical features, pathophysiology, and fluid characteristics of pleural effusion are reviewed. Studies reporting pneumothorax and pneumomediastinum are examined to evaluate for pathogenesis and prognosis. A brief comparative analysis of pleural abnormalities among patients with COVID-19, severe acute respiratory syndrome (SARS), and Middle Eastern respiratory syndrome (MERS) has been provided.

Conclusions: Radiologic pleural abnormalities are common in COVID-19, but the incidence of pleural effusion appears to be low. Pneumothorax is rare and does not independently predispose the patient to worse outcomes. SARS-CoV-2 infects the pleural space; however, whether the pleural fluid can propagate the infection is unclear.

Keywords: COVID-19; pleura; pleural effusion; pneumothorax; radiology

Submitted Mar 27, 2021. Accepted for publication Jun 25, 2021.

doi: $10.21037 /$ jtd-21-542

View this article at: https://dx.doi.org/10.21037/jtd-21-542

\section{Introduction}

Severe acute respiratory syndrome coronavirus 2 (SARSCov-2) is a novel beta coronavirus responsible for coronavirus disease 19 or COVID-19, the culprit of a currently ongoing pandemic (1). Unlike the two previous novel coronavirus outbreaks, COVID-19 has reached global proportion, claiming the lives of millions worldwide (2).

As a respiratory pathogen, the SARS-Cov-2 infection typically begins in the upper airway. The viral spike protein binds to the angiotensin-converting enzyme 2 (ACE-2) receptor and initiates an inflammatory response and cytopathic effects. In a minority of patients, the infection involves the lower respiratory tract (3). The most severe complication of SARS-CoV-2 is the development of pneumonia and acute respiratory distress syndrome. Additionally, pulmonary vascular endothelium may also be affected by SARS-CoV-2, causing endothelialitis and 
microangiopathy (4).

Pleural abnormalities in COVID-19 are either less common or underappreciated. Localized pleural thickening adjacent to the parenchymal lesion and pleural retraction is seen in early disease. Pleural effusion occurs in a minority of patients. Potentially life-threatening complications, such as pneumothorax, are uncommon. The purpose of this manuscript is to review the literature regarding the pleural space abnormalities that have been reported in COVID-19. We will inform the reader regarding the incidence, clinical manifestations, pathogenesis and radiologic appearance of the pleural diseases in SARS-CoV-2 infection. The manuscript also briefly compares the observed abnormalities with severe acute respiratory syndrome (SARS), Middle East Respiratory Syndrome (MERS), and other seasonal respiratory viruses.

We present the following article in accordance with the Narrative Review reporting checklist (available at https:// dx.doi.org/10.21037/jtd-21-542).

\section{Methods}

The Medline and PubMed databases were searched between January 2020 and June $5^{\text {th, }} 2021$ with the following search terms to identify relevant papers for this review: 'COVID-19 AND pleura'; 'COVID-19 AND pleural abnormalities'; 'COVID-19 AND pleural effusion'; 'COVID-19 AND pneumothorax'; and 'COVID-19 AND pneumomediastinum'. In addition, manuscripts pertinent to SARS and MERS infections were collected, searching the same databases between 2002-2021 with search terms 'severe acute respiratory syndrome AND pleural disease'; 'severe acute respiratory syndrome AND pleura'; 'SARS AND pleural disease'; 'middle east respiratory syndrome AND pleural disease'; 'middle east respiratory syndrome AND pleura' and 'MERS AND pleural disease'. Finally, the bibliography of the identified papers was thoroughly reviewed for additional articles of interest. Case reports, case series, observational cohort, retrospective studies, meta-analysis, and review articles were examined for this review. Primarily the data from adult patients were used for this study. Manuscripts in the non-English language were not evaluated.

\section{Discussion}

\section{Pleural abnormalities on transverse imaging in COVID-19}

Since the beginning of the pandemic, clinicians have utilized radiologic abnormalities to diagnose and assess the severity of COVID-19 $(5,6)$. Although parenchymal findings have received more attention, pleural involvement has been shown to be associated with disease severity and overall prognosis. Common thoracic radiologic findings in COVID-19 are summarized in Table 1 (7-10).

In the early reports of radiologic chest abnormalities with COVID-19, no significant pleural abnormalities were noted (11). However, these findings soon began to change. $\mathrm{Xu}$ et al. found that the majority of patients (56\%) had localized pleural thickening on the initial computed tomographic (CT) scan following hospital admission (12). Similarly, Zhou et al. reported pleural thickening in $49 \%$ of patients. In addition, pleural retraction was noted in more than half of the patients (56\%) (13). Pleural thickening and retraction were present both in the early $(\leq 7$ days after symptom onset) and late disease with similar frequencies (13). On the contrary, several studies reported no evidence of pleural thickening or retraction when the imaging study was obtained within 3-5 days (14-16). A meta-analysis reported a $34.7 \%$ pooled prevalence of pleural thickening (17). Figure 1 demonstrates radiographic appearance of early pleural changes.

A systematic review that included 919 patients reported pleural effusion and pneumothorax (Figure 2) to be late features that likely represent disease progression (18). The most severe radiologic manifestations involving the pulmonary parenchyma were seen around day ten in this study (18). Mo et al. reported bilateral pneumonia and pleural effusions to be associated with refractory disease (19). Many observational studies, systematic reviews, and meta-analyses have been published regarding radiologic abnormalities in COVID-19. Table 2 summarizes previously published meta-analyses with a relatively large patient population that reported the prevalence of pleural and nonpulmonary parenchymal abnormalities (17,20-23). Figure 2 represents pleural changes associated with progressive disease.

Magnetic resonance imaging (MRI) has been reported to be sensitive and specific to identify parenchymal, pleural, and mediastinal abnormalities in COVID-19. The authors have described diffuse GGO, pleural effusion, and lymphadenopathy by MRI. MRI provides the benefit of no radiation exposure. However, this technique is limited by the cost and significantly longer duration required to obtain the images, which may not be feasible in critically ill patients $(24,25)$.

Autopsy studies have revealed pleural involvement 
Table 1 Chest computed tomographic abnormalities in COVID-19 (7-10)

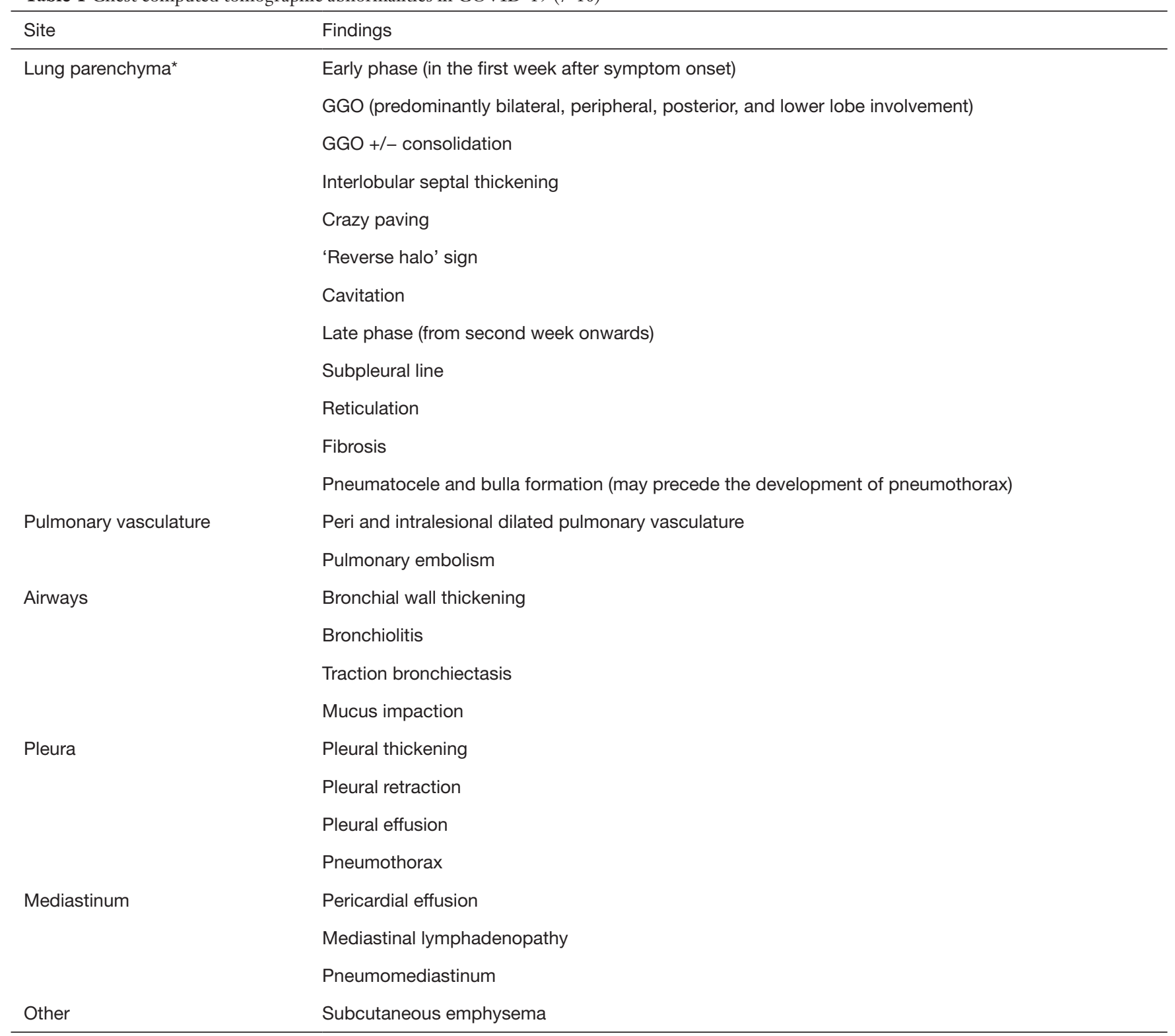

*The parenchymal changes do not follow strict time frame and may overlap. GGO, ground glass opacity.

concordant with radiologic findings. Carsana et al. reported autopsy findings of thirty-eight patients from Italy. In their report, the authors did not observe a pleural abnormality in any of the patients (26). However, pleural abnormalities have been noted in other autopsy studies. Barton $e t$ al. reported macroscopic pleural adhesion in an elderly male (27). Right-sided pleural adhesion was also noted by Navarro Conde et al. (28). Similarly, a report from Japan showed pleural thickening (29). Pleural effusion was seen during autopsies as well (30).

\section{Ultrasound findings of pleural involvement}

Chest ultrasound (CUS) is a sensitive tool for identifying SARS-CoV-2 induced pulmonary changes and correlates well with transverse imaging (31). Ultrasound evaluation can be performed at the bedside, and the risk associated with travel outside the intensive care unit (ICU) is avoided 

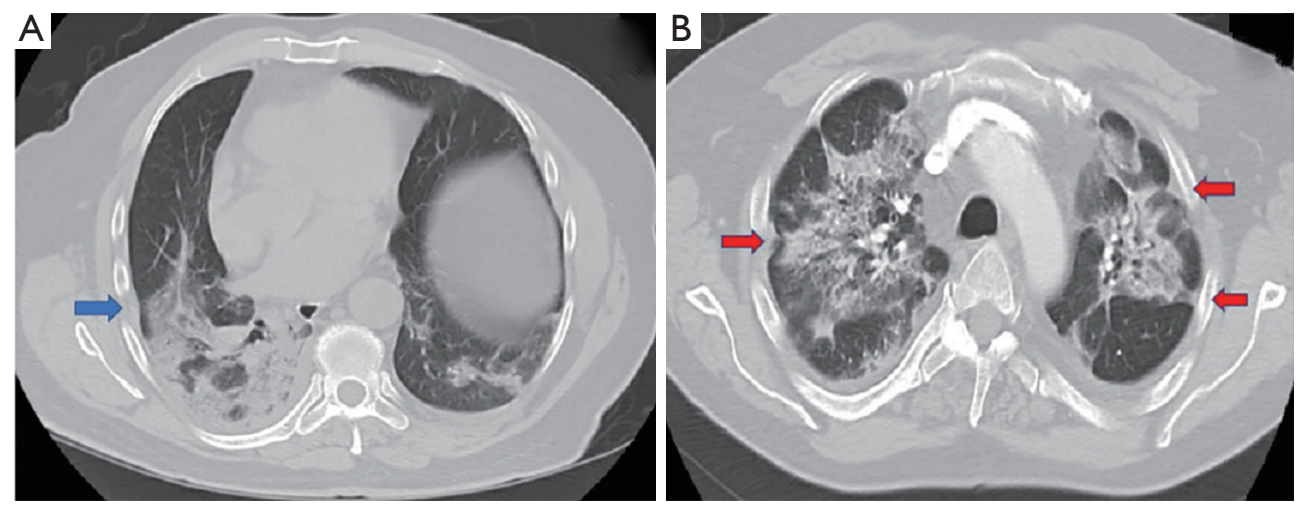

Figure 1 Axial chest imaging with pleural changes often seen in early disease. (A) CT chest in a 70-year old male obtained 5 days following hospitalization showed pleural thickening (blue arrow) adjacent to subpleural parenchymal infiltrate. (B) CT scan of the chest in a 55-year old male seven days after admission demonstrated bilateral pleural retraction (red arrow).
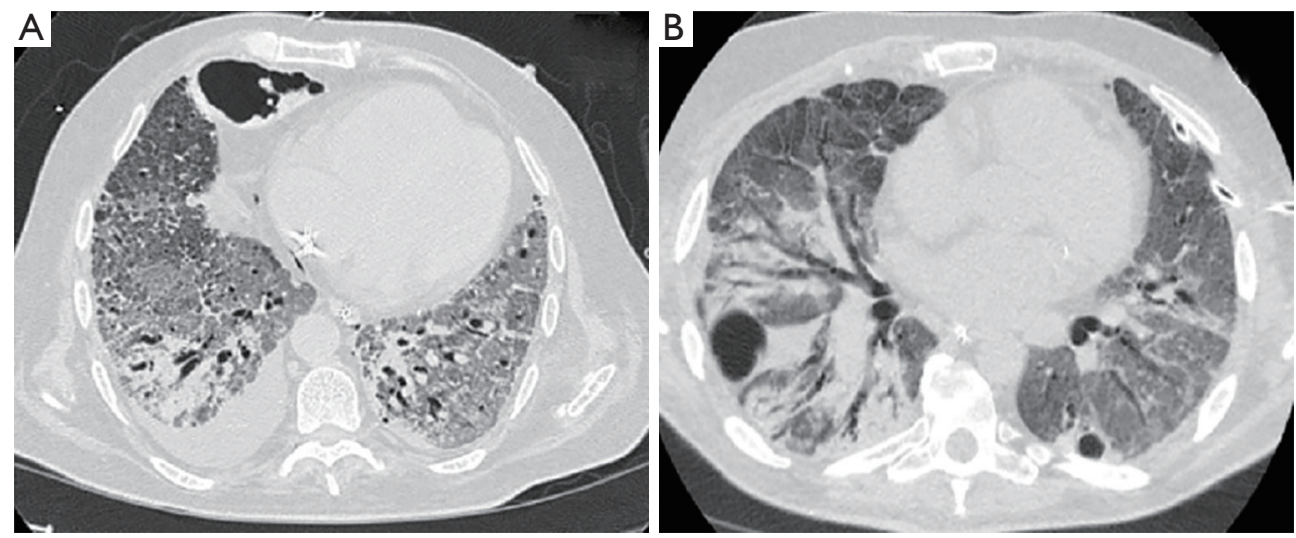

Figure 2 Pleural involvement in progressive late disease. (A) Axial CT scan of the chest four weeks following hospitalization in a 60 -year old man without any comorbidities revealed a small right sided pleural effusion. Advanced fibrotic changes with traction bronchiectasis was present bilaterally. Parenchymal destruction with pneumatocele formation was noted in the anterior right chest. (B) CT scan of the chest in a 51-year old male 30 days after hospitalization demonstrated bilateral pneumatocele formation. The patient developed a left sided pneumothorax and underwent small bore chest tube placement. Advanced pulmonary parenchymal changes were also seen.

in the critically ill. Thus, this real-time imaging modality might provide a safer diagnostic and prognostic tool (32). A structured approach in patients with COVID-19 has demonstrated reliable sensitivity and specificity in the diagnosis and prognosis of the disease (33). Lichter et al. reported pleural thickening as the most common pleural abnormality detected on CUS. Since peripheral airspace opacity is common with COVID-19, subpleural microconsolidation is often seen (34). Pleural irregularity or 'punctate pleura' likely corresponds to the pleural adhesion. A computerized system with automated analysis of the various aspects of the 'pleural line' such as thickness, thickness variation, non-linearity, margin tortuosity, and heterogeneity showed a high degree of sensitivity (35). Sparse or confluent 'B lines' correlate with GGO seen on CT scan. Patients with COVID-19 demonstrated higher echo intensity and lower heterogeneity of the ' $\mathrm{B}$ lines' compared to normal subjects (35). The CUS demonstrates higher sensitivity for the identification of pleural effusion compared to a chest X-ray. However, pleural effusion was reported rarely in US studies (34). 
Table 2 Meta-analyses with pleural and non-pulmonary parenchymal abnormalities

\begin{tabular}{|c|c|c|c|c|c|c|c|c|}
\hline Study & $\begin{array}{l}\text { Number of } \\
\text { studies }\end{array}$ & $\begin{array}{l}\text { Number of } \\
\text { patients }\end{array}$ & $\begin{array}{l}\text { Positive CT scans as } \\
\text { defined by studies (\%) }\end{array}$ & $\begin{array}{c}\text { Pleural } \\
\text { thickening (\%) }\end{array}$ & $\begin{array}{c}\text { Pleural } \\
\text { retraction (\%) }\end{array}$ & $\begin{array}{c}\text { Pleural } \\
\text { effusion (\%) }\end{array}$ & $\begin{array}{l}\text { Pericardial } \\
\text { effusion (\%) }\end{array}$ & $\begin{array}{c}\text { Mediastinal } \\
\text { lymphadenopathy (\%) }\end{array}$ \\
\hline $\begin{array}{l}\text { Bao } \\
\text { et al. (20) }\end{array}$ & 13 & 2,738 & 89.76 & 52.46 & NS & 5.88 & 4.55 & 3.38 \\
\hline $\begin{array}{l}\text { Zhu } \\
\text { et al. (21) }\end{array}$ & 34 & 4,124 & 91.6 & 27.1 & NS & 5.3 & NS & 5.4 \\
\hline $\begin{array}{l}\text { Adams } \\
\text { et al. (17) }\end{array}$ & 28 & 3,466 & 89.4 & 34.7 & NS & 5.2 & 2.7 & 5.1 \\
\hline $\begin{array}{l}\text { Xie } \\
\text { et al. (23) }\end{array}$ & 90 & 16,526 & 95.9 & 29.8 & NS & 4.2 & 4.4 & 2.9 \\
\hline
\end{tabular}

CT, computed tomography; NS, not specified.

\section{Pleural effusion in COVID-19}

All pneumonia can be complicated by parapneumonic effusion. The incidence of parapneumonic effusion among hospitalized patients ranges from 10-21\% (36). Parapneumonic effusions are seen more frequently with bacterial pneumonia compared to viral pneumonia (37).

Invasion of the pulmonary parenchyma by SARS$\mathrm{CoV}-2$ results in intense inflammation that causes diffuse alveolar injury and endothelial damage by the inflammatory cells (38). This results in an increased interstitial fluid content due to leaky microvasculature. The interstitial fluid then reaches the pleural spaces by traversing the visceral pleura due to interstitial-pleural pressure gradient (39). Direct invasion by the virus, inflammation of the visceral pleural, and inflammatory cytokines increases the permeability of the pleural surfaces as well. Postmortem studies have revealed positive SARS-CoV-2 PCR from pleural fluid, suggesting a direct invasion of the pleural space by the virus and the potential risk of transmission during the handling of pleural fluid (40).

Pleural effusion is a relatively uncommon finding among patients with COVID-19. Based on the reported case series and meta-analyses, the incidence has typically varied between 2-11\% (Table 2) (13,15-17,41-43). A systematic review that included 47 observational studies reported an overall incidence of $7.3 \%$ (44). However, several small and single center studies had reported an incidence exceeding $20 \%$ (45-48). A small pediatric study of 16 patients reported the imaging findings in multisystem inflammatory syndrome and found the incidence of pleural effusion to be as high as
$63 \%(49)$.

The effusion can be unilateral or bilateral, with the majority being unilateral $(44,50)$. The effusions are generally small to moderate sized, consistent with effusions seen with other viral pneumonia. The majority of patients developed the effusion in the second week of illness with associated lung parenchymal changes on chest imaging $(51,52)$.

The variability in the incidence could be due to the relative sickness among the studied patients. Pleural effusion in combination with severe parenchymal involvement may signify refractory disease and a higher incidence among severely ill patients (19,45,53-56). Liu et al. only observed pleural effusion in critically ill patients among a group of patients of different severity (57). Although patients older than 50 years had a higher incidence of pleural effusion in a study by Majidi et al., this finding was not validated by others $(42,58)$. It is crucial to emphasize that the determination of true causation of pleural effusion due to SARS-CoV-2 is challenging as many of these patients also suffer from co-morbid conditions known to cause pleural effusion, such as cardiovascular diseases, chronic kidney disease (CKD), pulmonary embolism, and secondary pulmonary infections (59). Interestingly, for patients in whom a second etiology for the effusion can be identified, the disease severity and prognosis might not be as critical. For example, patients with CKD infected with SARS-CoV-2 represent a unique group of patients. The mere presence of the effusion in these patients may not necessarily indicate severe disease. In fact, COVID-19 patients with CKD have been reported to have a higher incidence of pleural effusion $(21 \%)$, but with a mortality rate of $20 \%$, lower than expected mortality 
for critically ill patients (60). Similarly, a higher incidence of pleural effusions without any adverse outcomes have been reported in patients with advanced pregnancy. Gong et al. reported a sixty percent incidence of pleural effusion among pregnant patients with a gestational age of 36 weeks or higher (61). All effusions were small and bilateral. The authors theorized that increased vascular permeability at the late-stage pregnancy was likely responsible for the pleural effusion. In contrast, Zhang et al. reported that only $11 \%$ of patients with advanced pregnancy developed pleural effusion (62). None of these patients in these two studies had critical disease, and there was no mortality. Therefore, it can be suggested that the pleural effusion in COVID-19 that typically develops in the second or third week of illness, and is associated with significant parenchymal disease, likely represents severe disease with worse outcomes. However, patients in whom the effusion develops early, without severe parenchymal involvement and other potential explanation for the effusion, might have a good prognosis. Although critically ill patients with COVID-19 have increased odds of developing pleural effusion, the association between pleural effusion and mortality is uncertain at this time.

\section{Pleural fluid characteristics}

Few reports have described the characteristics of the pleural fluid in COVID-19 (63-66). In general, a parapneumonic effusion due to viral pneumonia demonstrates either a lymphocyte or neutrophilic predominance $(50,65,67)$. A neutrophilic effusion is more likely if the effusion develops early. Table 3 summarizes the results of pleural fluid analysis in COVID-19 patients.

The pleural fluid was serous or serosanguinous on gross inspection. Turbidity was noted in one report (66). Serosanguineous pleural effusion in patients on systemic anticoagulation may have represented procedural complications, rather than the actual appearance of the fluid. All patients with serosanguineous pleural fluid had undergone chest tube placement, which is more invasive and likely to cause more bleeding compared to a diagnostic thoracentesis (63).

Pleural fluid cellularity varied from a few hundred to a few thousand cells per microL. Interestingly, in the absence of serosanguinity, the pleural fluid was always lymphocytepredominant, and in some cases, the lymphocyte differential was above ninety percent. Some patients showed mixed cellularity or even neutrophilic predominance. The authors attributed the pleural fluid neutrophilia to systemic lymphopenia associated with COVID-19 (63). The other explanation for neutrophilic predominance was bleeding in the pleural cavity during the pleural fluid sampling due to the chest tube placement. An additional possibility would be hemorrhagic pleural effusion due to pleural infarction in the setting of thrombotic microangiopathy, a well-known complication of COVID-19.

Pleural fluid chemistry in COVID-19 has consistently been exudative. The LDH criteria were positive for all cases. The absolute values of LDH have varied significantly. In lymphocyte predominant serous effusion, the $\mathrm{LDH}$ has been in the hundreds compared to thousands in serosanguineous effusions (Table 3). This difference could be explained by the increased LDH level from the hemolyzed RBCs or exuberant inflammation of the pleural space by SARS-CoV-2. Chong et al. reported a higher pleural fluid LDH level in their patients compared to the serum (63). A pleural fluid/serum LDH $>1$ has previously been reported in patients with Pneumocystis pleural effusion (69). Unfortunately, not many reports of pleural fluid analysis exist in the current literature. It is important to emphasize that both qualitative and quantitative PCR for SARS-CoV-2 have been positive in alive patients and on autopsy $(64,68)$. This indicates that active infection of the pleural space by the virus is likely responsible for the effusion in addition to the increased vascular and mesothelial permeability (59). Whether the pleural fluid can be a source of disease transmission is currently uncertain. Pleural fluid cytology has consistently revealed mesothelial cells and mature lymphocytes. Atypical lymphocytosis has not been reported.

\section{Pneumothorax in COVID-19}

Pneumothorax appears to be a rare occurrence in COVID-19. Earlier studies estimated the incidence to be approximately $1 \%$ (70). Several large meta-analyses that evaluated radiologic presentations of COVID-19 did not report any case of pneumothorax (20-22). However, these meta-analyses comprised of studies that included patients for whom the CT scan was obtained relatively early during the disease process. As the available data points towards a late occurrence for pneumothorax, this data may have been misleading. Similarly, the incidence of pneumothorax likely varies depending on the disease severity.

Spontaneous pneumothorax has been reported in nonintubated as well as mechanically ventilated patients (71-78). A recent systematic review estimated an overall incidence of pneumothorax at $0.3 \%$ among all hospitalized patients 


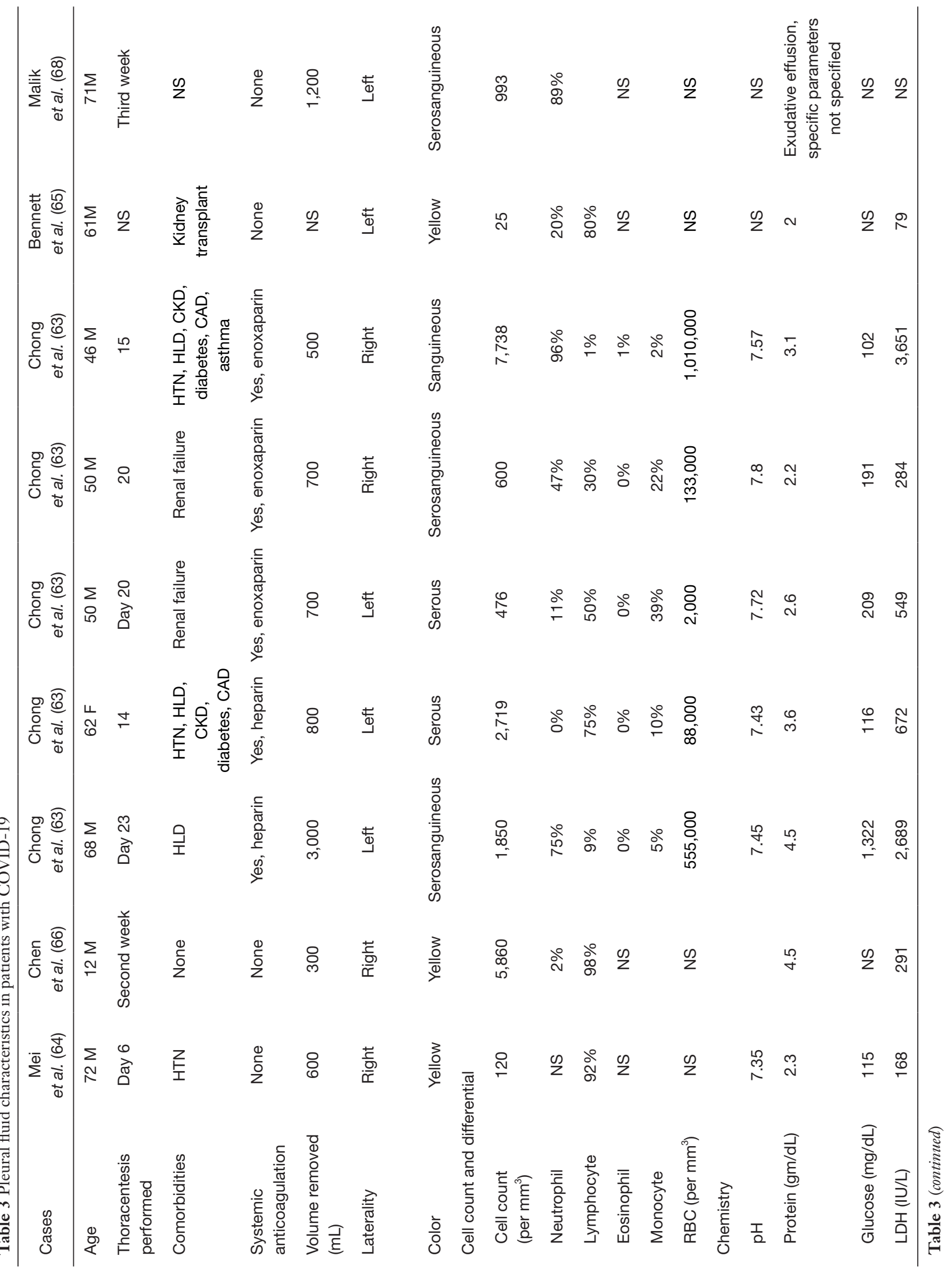




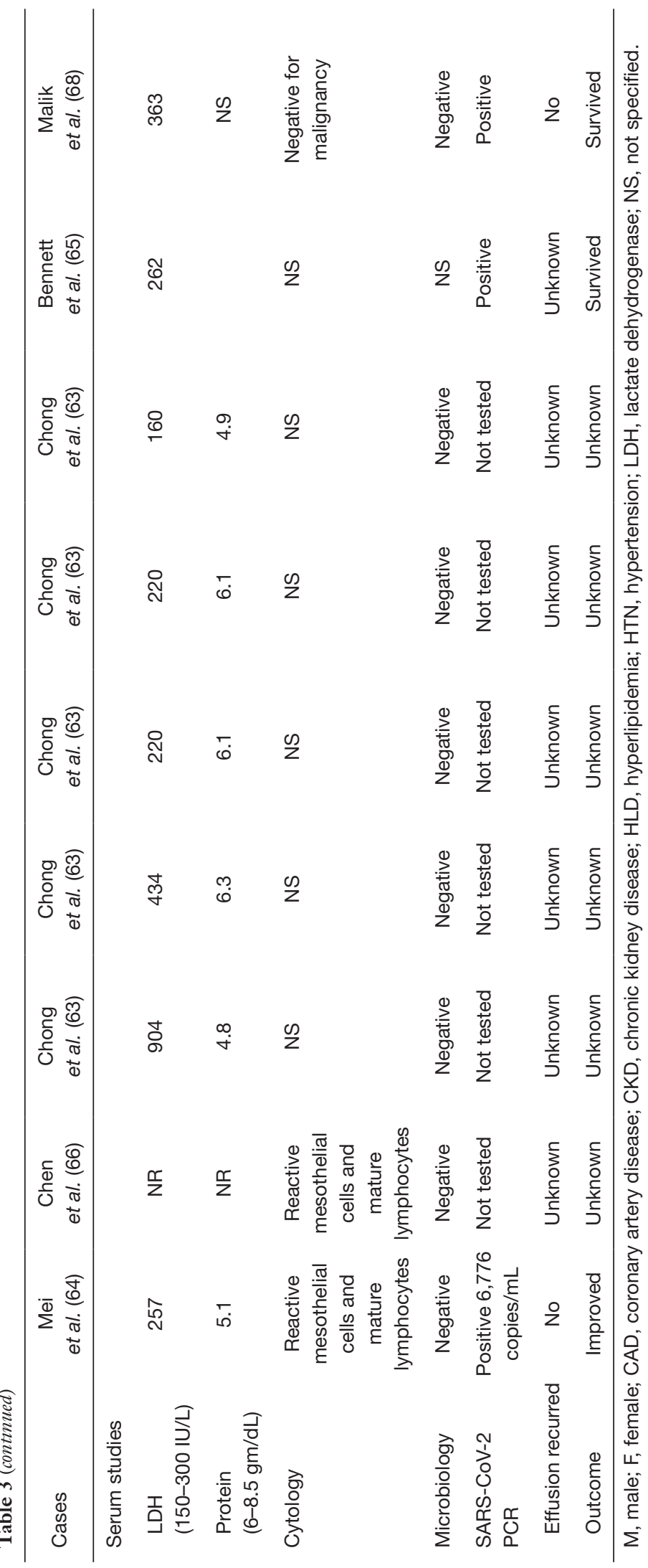


with COVID-19 (79). For critically ill patients, the incidence increased to $2 \%$ (80). However, the rate is much higher in critically ill patients, especially patients requiring mechanical ventilation (Table 4) (81-86). The onset of pneumothorax was variable among studies. Overall, the diagnosis of pneumothorax varied between 9-19.6 days after hospital admission and 5.4 to 11 days following initiation of mechanical ventilation. Interestingly, the overwhelming majority of patients were males in their fifth and sixth decades. The pneumothorax was most commonly unilateral, affecting the right side. A minority of patients suffered from bilateral pneumothoraces. Preexisting lung disease and smoking were not distinctly associated with an increased risk for developing pneumothorax $(80,83)$. Isolated or concurrent pneumomediastinum with pneumothorax was also reported. Quincho-Lopez et al. reported a $60 \%$ mortality when patients presented with concurrent pneumothorax and pneumomediastinum, but the sample size consisted of only five patients (87). A limited number of studies have assessed the relationship between ventilatory parameters and risks of barotrauma in mechanically ventilated patients. Based on the available data, the risk of pneumothorax was not higher in patients with higher peak inspiratory pressure, plateau pressure, or tidal volume, suggesting that severity of lung disease rather than ventilator strategies may be responsible $(85,88)$.

The development of pneumothorax in non-mechanically ventilated patients also argues against barotrauma being the only culprit. Some authors have suggested that prolonged coughing may be contributory (88). Although static lung compliance in acute respiratory distress syndrome (ARDS) due to COVID-19 pneumonia may be initially high, patients with advanced ARDS lasting more than a week often have low lung compliance, similar to ARDS from other etiologies $(89,90)$. Low lung compliance and prolonged duration of mechanical ventilation in non-COVID-19 ARDS have been associated with a higher incidence of pneumothorax $(91,92)$. The incidence of pneumothorax in non-COVID-19 ARDS has ranged from $0-49 \%$ (91). The high frequency of barotrauma was likely related to high tidal volume ventilation that was routinely used before the universal implementation of lung protective ventilatory strategies in ARDS. Miller et al. reported a significant reduction in the risk of pneumothorax in children with the adoption of low tidal volume ventilation (55\% versus $17 \%$ ) (93). Based on historical data, the incidence of pneumothorax in mechanically ventilated ARDS patients with or without COVID-19 appears comparable.
The exact pathogenesis of pneumothorax is uncertain. The occurrence of pneumomediastinum, pneumothorax, and subcutaneous emphysema may represent a different degree of severity of the same disease process. SARS-CoV-2 predominantly involves peripheral and subpleural lung parenchyma. The viral invasion, profound inflammation, and microangiopathy cause diffuse alveolar damage and hyaline membrane formation. The alveolar damage might cause air to leak through the alveoli that travel medially through the bronchovascular bundle and escape at the hilum to cause pneumomediastinum, similar to the Macklin effect. Macklin effect refers to the expulsion of alveolar air in the setting of increased intrathoracic pressure along the bronchovascular bundle, causing pneumomediastinum without any pneumothorax (94). Conversely, if there is concomitant damage to the visceral pleura, the alveolar air might escape in the pleural space, causing a pneumothorax. Both pneumothorax and pneumomediastinum can eventually cause subcutaneous emphysema. In some cases, the formation of pneumatocele preceded the development of pneumothorax and might be clinically significant to identify patients at a higher risk $(73,95,96)$. There were also reports of rapidly developing the bullous disease (78).

The presentation of pneumothorax has been variable. Some patients had presented with tension pneumothorax requiring immediate evacuation of the pleural space, but there are also reports of incidentally identified cases. Most patients required tube thoracostomy, but approximately $30 \%$ of patients were managed successfully without needing pleural space evacuation (Table 4). Researchers have raised concerns regarding the possibility of aerosol generation and dissemination through the chest tube and water seal drainage system in patients requiring tube thoracostomy (97). Potential 'super spreading events' have been linked to chest tube drainage of the pleural space $(98,99)$. Indeed, an experimental study showed that the number of aerosolized particles increased with an increasing airflow simulating air leak through a bubbling chest tube (100). The use of an antiviral filter significantly reduced the number of aerosols escaping the experimental systems $(97,100)$. Despite these concerns, there has been no definitive proof of SARS$\mathrm{CoV}-2$ transmission among patients or healthcare workers from pleural space. However, it is prudent to routinely check patients for SARS-CoV-2 infection by RT-PCR prior to pleural procedures, such as pleuroscopy, and practice caution in patients with chest tubes until more detailed data becomes available (101).

Outcomes in patients with pneumothorax have varied 


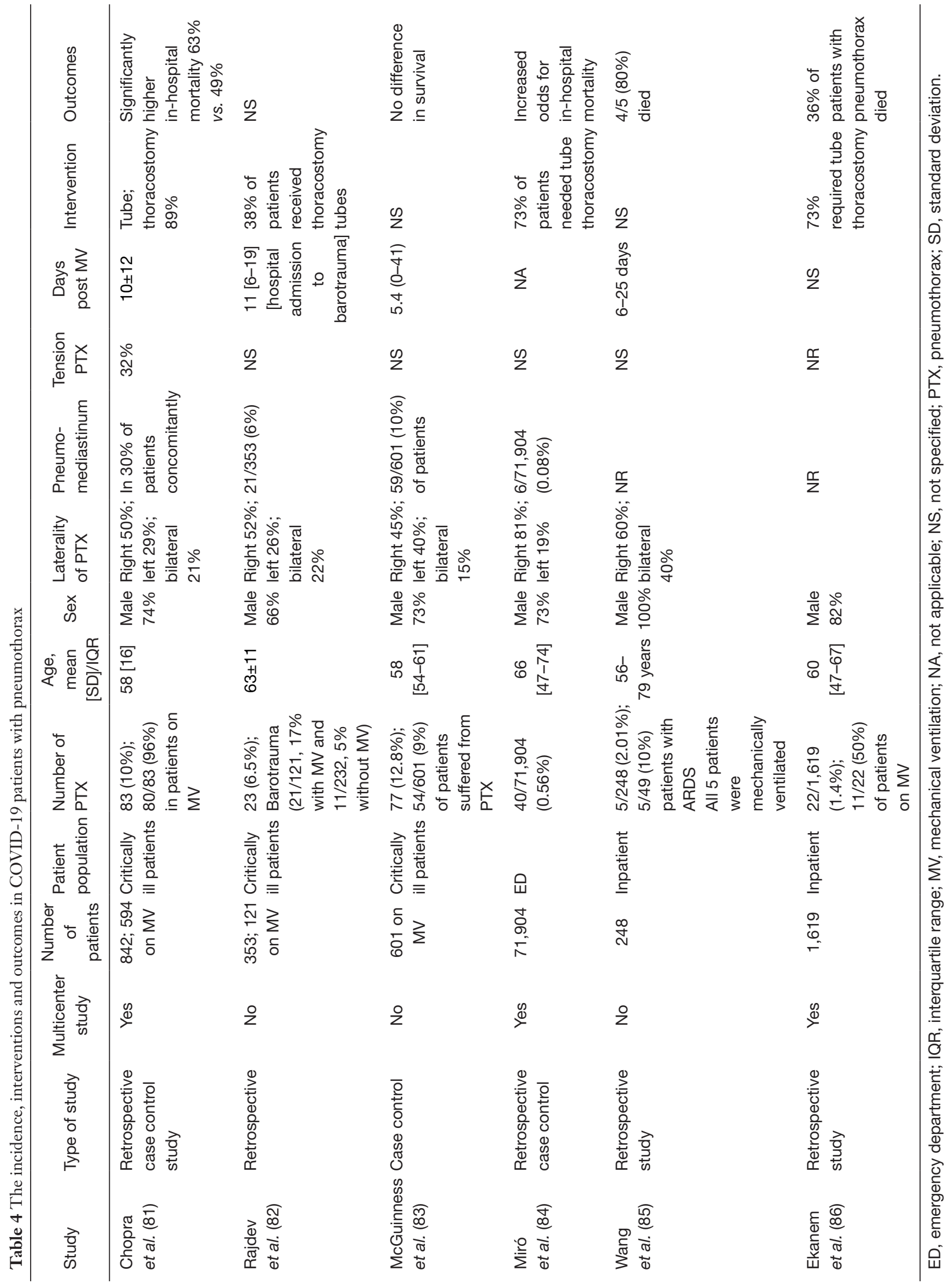


Table 5 Comparison of pleural and non-pulmonary parenchymal abnormalities in COVID-19, SARS, MERS, and influenza (102-111)

\begin{tabular}{|c|c|c|c|c|c|c|}
\hline Virus & Normal X-ray & Pleural effusion & $\begin{array}{l}\text { Effusion } \\
\text { characteristics }\end{array}$ & Pneumothorax & $\begin{array}{l}\text { Mediastinal } \\
\text { lymphadenopathy }\end{array}$ & $\begin{array}{c}\text { Overall } \\
\text { mortality (\%) }\end{array}$ \\
\hline COVID-19 & About $20 \%$ & $\begin{array}{l}4.2-5.8 \% \text { (typically } \\
\text { later in the disease) }\end{array}$ & $\begin{array}{l}\text { Lymphocyte } \\
\text { predominant, exudative }\end{array}$ & Approximately $1 \%$ & $2.9-5.4 \%$ & $1-3$ \\
\hline SARS & $\sim 20 \%$ & $\begin{array}{l}26 \% \text { (typically later in } \\
\text { the disease) }\end{array}$ & Not reported & $11 \%$ & Not reported & 9 \\
\hline Influenza & Unknown & 20-36\%, early & Lymphocyte predominant & Very rare & Approximately $20 \%$ & 0.1 \\
\hline
\end{tabular}

COVID-19, coronavirus disease 19; MERS, middle east respiratory syndrome; SARS, severe acute respiratory syndrome.

among studies. Several observational studies revealed an increased length of hospital stay compared to patients without pneumothorax $(83,86)$. Increased risk of ICU admissions and in-hospital mortality have been reported as well $(81,84)$. In contrast, McGuinness et al. reported no difference in mortality among mechanically ventilated patients with or without barotrauma (83). Similarly, a larger retrospective cohort study by Martinelli et al. showed no significant mortality difference between patients with or without a pneumothorax or pneumomediastinum (80).

\section{Pleural involvement with other viruses and relative comparison with COVID-19}

The other novel coronaviruses, SARS and MERS are known to cause pleural disease. The incidence of pleural effusion and pneumothorax appears to be higher in SARS. Although no pleural changes were identified in early diseases with SARS $(102,103)$, significant pleural pathology developed when the patients survived beyond two weeks. Chan et al. reported pleural thickening, effusion (26\%), and spontaneous pneumomediastinum (26\%), with or without associated pneumothorax (11\% of all patients) in their cohort of 27 patients with SARS (104). In case of MERS, the pleural effusion was often seen early, within the first week of infection. The overall incidence ranged between $33-55 \%$ and is likely much higher than SARS CoV-2 (105). The presence of pleural effusion was associated with worse outcomes $(105,106)$. One study reported fatal outcomes in all patients who had pleural effusion (107). Pneumothorax was a fatal complication of MERS. Although rare, the development of pneumothorax predicted fatality in nearly all patients with MERS (108). Both pleural effusion and pneumothorax were found to be independent predictors of mortality in MERS (106).

Seasonal coronaviruses, such as 229E, NL63, OC43, and HKU1 strains are uncommon causes of lower respiratory tract infection and pleural involvement by these strains is not frequently described (109). Pleural effusion is infrequent with community acquired viral pneumonia and, when present, is typically small. The incidence ranges between $14-33 \%$. Both unilateral and bilateral cases of pleural effusion have been reported $(110,111)$. Pneumothorax is a rare complication. The incidence of pneumothorax from seasonal Influenza is much lower than SARS-CoV-2 (112). Table 5 provides a comparative analysis of pleural space disease in COVID-19, SARS, MERS and Influenza.

\section{Conclusions}

Pleural abnormalities are frequently present in patients with COVID-19. Localized pleural thickening and retraction are common early findings on radiologic imaging. Pleural effusion is an uncommon complication of SARS-CoV-2 pneumonia and typically develops later in the disease process. The determination of true causation of pleural effusion by SARS-CoV-2 may be challenging in the presence of coexistent comorbidities. Nonetheless, the detection of SARS-CoV-2 RNA in the pleural fluid is likely indicative of pleural space invasion by the virus. The pleural fluid is exudative with either lymphocytic or neutrophilic predominance. The presence of pleural effusion in addition to severe parenchymal involvement is associated with severe disease and likely portends a poorer outcome. Pneumothorax appears to be rare in COVID-19. The incidence is higher in critically ill patients, especially in patients requiring mechanical ventilation. However, the risk of pneumothorax in these patients is 
comparable to historical non-COVID-19 ARDS patients. The exact pathogenesis is unclear, but the development of pneumatocele or bullae may precede pneumothorax. Whether pneumothorax portends worse mortality is debatable. Chest tube evacuation of the pleural space in the presence of air leak may be associated with aerosol generation-however, the risk of disease transmission via this route is uncertain. Until more definitive data is available, it would be prudent to practice caution.

\section{Acknowledgments}

Funding: None.

\section{Footnote}

Reporting Checklist: The authors have completed the Narrative Review reporting checklist. Available at https:// dx.doi.org/10.21037/jtd-21-542

Peer Review File: Available at https://dx.doi.org/10.21037/ jtd-21-542

Conflicts of Interest: All authors have completed the ICMJE uniform disclosure form (available at https://dx.doi. org/10.21037/jtd-21-542). The authors have no conflicts of interest to declare.

Ethical Statement: The authors are accountable for all aspects of the work in ensuring that questions related to the accuracy or integrity of any part of the work are appropriately investigated and resolved.

Open Access Statement: This is an Open Access article distributed in accordance with the Creative Commons Attribution-NonCommercial-NoDerivs 4.0 International License (CC BY-NC-ND 4.0), which permits the noncommercial replication and distribution of the article with the strict proviso that no changes or edits are made and the original work is properly cited (including links to both the formal publication through the relevant DOI and the license). See: https://creativecommons.org/licenses/by-nc-nd/4.0/.

\section{References}

1. Zheng J. SARS-CoV-2: an Emerging Coronavirus that Causes a Global Threat. Int J Biol Sci 2020;16:1678-85.

2. Feehan J, Apostolopoulos V. Is COVID-19 the worst pandemic? Maturitas [Internet]. 2021 Feb 6 [cited 2021 Jun 8]. Available online: https://www.ncbi.nlm.nih.gov/ pmc/articles/PMC7866842/

3. Saha BK, Bonnier A, Chong W. Antimalarials as Antivirals for COVID-19: Believe it or Not! Am J Med Sci 2020;360:618-30.

4. Ackermann M, Verleden SE, Kuehnel M, et al. Pulmonary Vascular Endothelialitis, Thrombosis, and Angiogenesis in Covid-19. N Engl J Med 2020;383:120-8.

5. Fang Y, Zhang H, Xie J, et al. Sensitivity of Chest CT for COVID-19: Comparison to RT-PCR. Radiology 2020;296:E115-7.

6. Yang R, Li X, Liu H, et al. Chest CT Severity Score: An Imaging Tool for Assessing Severe COVID-19. Radiol Cardiothorac Imaging 2020;2:e200047.

7. Bernheim A, Mei X, Huang M, et al. Chest CT Findings in Coronavirus Disease-19 (COVID-19): Relationship to Duration of Infection. Radiology 2020;295:200463.

8. Jin YH, Cai L, Cheng ZS, et al. A rapid advice guideline for the diagnosis and treatment of 2019 novel coronavirus (2019-nCoV) infected pneumonia (standard version). Mil Med Res 2020;7:4.

9. Siddiqi HK, Mehra MR. COVID-19 illness in native and immunosuppressed states: A clinical-therapeutic staging proposal. J Heart Lung Transplant 2020;39:405-7.

10. Polak SB, Van Gool IC, Cohen D, et al. A systematic review of pathological findings in COVID-19: a pathophysiological timeline and possible mechanisms of disease progression. Mod Pathol 2020;33:2128-38.

11. Chung M, Bernheim A, Mei X, et al. CT Imaging Features of 2019 Novel Coronavirus (2019-nCoV). Radiology 2020;295:202-7.

12. $\mathrm{Xu} \mathrm{X}, \mathrm{Yu} \mathrm{C}, \mathrm{Qu} J$, et al. Imaging and clinical features of patients with 2019 novel coronavirus SARS-CoV-2. Eur J Nucl Med Mol Imaging 2020;47:1275-80.

13. Zhou S, Wang Y, Zhu T, et al. CT Features of Coronavirus Disease 2019 (COVID-19) Pneumonia in 62 Patients in Wuhan, China. AJR Am J Roentgenol 2020;214:1287-94.

14. Lin L, Fu G, Chen S, et al. CT Manifestations of Coronavirus Disease (COVID-19) Pneumonia and Influenza Virus Pneumonia: A Comparative Study. AJR Am J Roentgenol 2021;216:71-9.

15. Xiang C, Lu J, Zhou J, et al. CT Findings in a Novel Coronavirus Disease (COVID-19) Pneumonia at Initial Presentation. Biomed Res Int 2020;2020:5436025.

16. Khaliq M, Raja R, Khan N, et al. An Analysis of HighResolution Computed Tomography Chest Manifestations of COVID-19 Patients in Pakistan. Cureus 2020;12:e9373. 
17. Adams HJA, Kwee TC, Yakar D, et al. Chest CT Imaging Signature of Coronavirus Disease 2019 Infection: In Pursuit of the Scientific Evidence. Chest 2020;158:1885-95.

18. Salehi S, Abedi A, Balakrishnan S, et al. Coronavirus Disease 2019 (COVID-19): A Systematic Review of Imaging Findings in 919 Patients. AJR Am J Roentgenol 2020;215:87-93.

19. Mo P, Xing Y, Xiao Y, et al. Clinical characteristics of refractory COVID-19 pneumonia in Wuhan, China. Clin Infect Dis 2020. [Epub ahead of print]. doi:10.1093/cid/ ciaa270.

20. Bao C, Liu X, Zhang H, et al. Coronavirus Disease 2019 (COVID-19) CT Findings: A Systematic Review and Meta-analysis. J Am Coll Radiol 2020;17:701-9.

21. Zhu J, Zhong Z, Li H, et al. CT imaging features of 4121 patients with COVID-19: A meta-analysis. J Med Virol 2020;92:891-902.

22. Ojha V, Mani A, Pandey NN, et al. CT in coronavirus disease 2019 (COVID-19): a systematic review of chest CT findings in 4410 adult patients. Eur Radiol 2020;30:6129-38.

23. Xie J, Wang Q, Xu Y, et al. Clinical characteristics, laboratory abnormalities and CT findings of COVID-19 patients and risk factors of severe disease: a systematic review and meta-analysis. Ann Palliat Med 2021;10:1928-49.

24. Langenbach MC, Hokamp NG, Persigehl T, et al. MRI appearance of COVID-19 infection. Diagn Interv Radiol 2020;26:377-8.

25. Ates OF, Taydas O, Dheir H. Thorax Magnetic Resonance Imaging Findings in Patients with Coronavirus Disease (COVID-19). Acad Radiol 2020;27:1373-8.

26. Carsana L, Sonzogni A, Nasr A, et al. Pulmonary postmortem findings in a series of COVID-19 cases from northern Italy: a two-centre descriptive study. Lancet Infect Dis 2020;20:1135-40.

27. Barton LM, Duval EJ, Stroberg E, et al. COVID-19 Autopsies, Oklahoma, USA. Am J Clin Pathol 2020;153:725-33.

28. Navarro Conde P, Alemany Monraval P, Medina Medina $\mathrm{C}$, et al. Autopsy findings from the first known death from Severe Acute Respiratory Syndrome SARS-CoV-2 in Spain. Rev Esp Patol 2020;53:188-92.

29. Adachi T, Chong JM, Nakajima N, et al. Clinicopathologic and Immunohistochemical Findings from Autopsy of Patient with COVID-19, Japan - Volume 26, Number 9 September 2020 - Emerging Infectious Diseases journal -
CDC. [cited 2020 Sep 6]. Available online: https://wwwnc. cdc.gov/eid/article/26/9/20-1353_article

30. Calabrese F, Pezzuto F, Fortarezza F, et al. Pulmonary pathology and COVID-19: lessons from autopsy. The experience of European Pulmonary Pathologists. Virchows Arch 2020;477:359-72.

31. Ottaviani S, Franc M, Ebstein E, et al. Lung ultrasonography in patients with COVID-19: comparison with CT. Clin Radiol 2020;75:877.e1-6.

32. Ticinesi A, Scarlata S, Nouvenne A, et al. The Geriatric Patient: The Ideal One for Chest Ultrasonography? A Review From the Chest Ultrasound in the Elderly Study Group (GRETA) of the Italian Society of Gerontology and Geriatrics (SIGG). J Am Med Dir Assoc 2020;21:447454.e6.

33. Lichter Y, Topilsky Y, Taieb P, et al. Lung ultrasound predicts clinical course and outcomes in COVID-19 patients. Intensive Care Med 2020:1-11.

34. Nouvenne A, Zani MD, Milanese G, et al. Lung Ultrasound in COVID-19 Pneumonia: Correlations with Chest CT on Hospital admission. Respiration 2020;99:617-24.

35. Sultan LR, Chen Y'T, Cary TW, et al. Quantitative pleural line characterization outperforms traditional lung texture ultrasound features in detection of COVID-19. J Am Coll Emerg Physicians Open 2021;2:e12418.

36. Falguera $M$, Carratalà J, Bielsa S, et al. Predictive factors, microbiology and outcome of patients with parapneumonic effusion. Eur Respir J 2011;38:1173-9.

37. Sahn SA. Diagnosis and management of parapneumonic effusions and empyema. Clin Infect Dis 2007;45:1480-6.

38. Schaller T, Hirschbühl K, Burkhardt K, et al. Postmortem Examination of Patients With COVID-19. JAMA 2020;323:2518-20.

39. Sahn SA. The pathophysiology of pleural effusions. Annu Rev Med 1990;41:7-13.

40. Ducloyer M, Gaborit B, Toquet C, et al. Complete post-mortem data in a fatal case of COVID-19: clinical, radiological and pathological correlations. Int J Legal Med 2020;134:2209-14.

41. Fu Z, Tang N, Chen Y, et al. CT features of COVID-19 patients with two consecutive negative RT-PCR tests after treatment. Sci Rep 2020;10:11548.

42. Majidi H, Bani-Mostafavi ES, Mardanshahi Z, et al. Highresolution computed tomography finding in 552 patients with symptomatic COVID-19: first report from north of Iran. Emerg Radiol 2020;27:633-9.

43. Liu X, Zhou H, Zhou Y, et al. Temporal radiographic 
changes in COVID-19 patients: relationship to disease severity and viral clearance. Sci Rep 2020;10:10263.

44. Chong WH, Saha BK, Conuel E, et al. The incidence of pleural effusion in COVID-19 pneumonia: State-of-theart review. Heart Lung 2021;50:481-90.

45. Arentz M, Yim E, Klaff L, et al. Characteristics and Outcomes of 21 Critically Ill Patients With COVID-19 in Washington State. JAMA 2020;323:1612-4.

46. Colombi D, Bodini FC, Petrini M, et al. Well-aerated Lung on Admitting Chest CT to Predict Adverse Outcome in COVID-19 Pneumonia. Radiology 2020;296:E86-96.

47. Gervaise A, Bouzad C, Peroux E, et al. Acute pulmonary embolism in non-hospitalized COVID-19 patients referred to CTPA by emergency department. Eur Radiol 2020;30:6170-7.

48. Pakdemirli E, Mandalia U, Monib S. Characteristics of Chest CT Images in Patients With COVID-19 Pneumonia in London, UK. Cureus 2020;12:e10289.

49. Blumfield E, Levin TL, Kurian J, et al. Imaging Findings in Multisystem Inflammatory Syndrome in Children (MIS-C) Associated With Coronavirus Disease (COVID-19). AJR Am J Roentgenol 2021;216:507-17.

50. Malik J, Javed N, Naeem H, et al. COVID-19 Associated Pneumonia and Pleural Effusion Masquerading as Heart Failure in Rheumatic Heart Disease. Eur J Case Rep Intern Med 2020;7:001842.

51. Xiong Y, Sun D, Liu Y, et al. Clinical and High-Resolution CT Features of the COVID-19 Infection: Comparison of the Initial and Follow-up Changes. Invest Radiol 2020;55:332-9.

52. Wang Y, Dong C, Hu Y, et al. Temporal Changes of CT Findings in 90 Patients with COVID-19 Pneumonia: A Longitudinal Study. Radiology 2020;296:E55-64.

53. Zheng Y, Wang L, Ben S. Meta-analysis of chest CT features of patients with COVID-19 pneumonia. J Med Virol 2021;93:241-9.

54. Li K, Wu J, Wu F, et al. The Clinical and Chest CT Features Associated With Severe and Critical COVID-19 Pneumonia. Invest Radiol 2020;55:327-31.

55. Feng Y, Ling Y, Bai T, et al. COVID-19 with Different Severities: A Multicenter Study of Clinical Features. Am J Respir Crit Care Med 2020;201:1380-8.

56. Zhan N, Guo Y, Tian S, et al. Clinical characteristics of COVID-19 complicated with pleural effusion. BMC Infect Dis 2021;21:176.

57. Liu KC, Xu P, Lv WF, et al. CT manifestations of coronavirus disease-2019: A retrospective analysis of 73 cases by disease severity. Eur J Radiol 2020;126:108941.
58. Zhu T, Wang Y, Zhou S, et al. A Comparative Study of Chest Computed Tomography Features in Young and Older Adults With Corona Virus Disease (COVID-19). J Thorac Imaging 2020;35:W97-W101.

59. Porcel JM. Pleural diseases and COVID-19: ubi fumus, ibi ignis. Eur Respir J 2020;56:2003308.

60. Abrishami A, Khalili N, Dalili N, et al. Clinical and Radiologic Characteristics of COVID-19 in Patients With CKD. Iran J Kidney Dis 2020;14:267-77.

61. Gong X, Song L, Li H, et al. CT characteristics and diagnostic value of COVID-19 in pregnancy. PLoS One 2020;15:e0235134.

62. Zhang L, Dong L, Ming L, et al. Severe acute respiratory syndrome coronavirus 2(SARS-CoV-2) infection during late pregnancy: a report of 18 patients from Wuhan, China. BMC Pregnancy Childbirth 2020;20:394.

63. Chong WH, Huggins JT, Chopra A. Characteristics of Pleural Effusion in Severe Acute Respiratory Syndrome Coronavirus 2 (SARS-CoV-2) Pneumonia. Am J Med Sci 2021;361:281-4.

64. Mei F, Bonifazi M, Menzo S, et al. First Detection of SARS-CoV-2 by Real-Time Reverse TranscriptasePolymerase Chain Reaction Assay in Pleural Fluid. Chest 2020;158:e143-6.

65. Bennett D, Franchi F, De Vita E, et al. SARS-CoV-2 in pleural fluid in a kidney transplant patient. Postgrad Med 2021;133:540-3.

66. Chen HR, Zou H, Xue M, et al. A Case of Childhood COVID-19 Infection with Pleural Effusion Complicated by Possible Secondary Mycoplasma Pneumoniae Infection. Pediatr Infect Dis J 2020;39:e135-7.

67. Karkhanis VS, Joshi JM. Pleural effusion: diagnosis, treatment, and management. Open Access Emerg Med 2012;4:31-52.

68. Malik MI, Fox N, Chopra A, et al. Positive pleural fluid RT-PCR for virus detection in SARS-CoV-2 pneumonia. QJM Int J Med [Internet]. 2020 Sep 16 [cited 2021 Mar 24]. Available online: https://www.ncbi.nlm.nih.gov/pmc/ articles/PMC7546120/

69. Horowitz ML, Schiff M, Samuels J, et al. Pneumocystis carinii pleural effusion. Pathogenesis and pleural fluid analysis. Am Rev Respir Dis 1993;148:232-4.

70. Chen N, Zhou M, Dong X, et al. Epidemiological and clinical characteristics of 99 cases of 2019 novel coronavirus pneumonia in Wuhan, China: a descriptive study. Lancet 2020;395:507-13.

71. Manna S, Maron SZ, Cedillo MA, et al. Spontaneous subcutaneous emphysema and pneumomediastinum in 
non-intubated patients with COVID-19. Clin Imaging 2020;67:207-13.

72. do Lago VC, Cezare TJ, Fortaleza CMCB, et al. Does COVID-19 Increase the Risk for Spontaneous Pneumothorax? Am J Med Sci 2020;360:735-7.

73. Mallick T, Dinesh A, Engdahl R, et al. COVID-19 Complicated by Spontaneous Pneumothorax. Cureus 2020;12:e9104.

74. Ucpinar BA, Sahin C, Yanc U. Spontaneous pneumothorax and subcutaneous emphysema in COVID-19 patient: Case report. J Infect Public Health 2020;13:887-9.

75. Wang W, Gao R, Zheng Y, et al. COVID-19 with spontaneous pneumothorax, pneumomediastinum and subcutaneous emphysema. J Travel Med 2020;27:taaa062.

76. Flower L, Carter JL, Rosales Lopez J, et al. Tension pneumothorax in a patient with COVID-19. BMJ Case Rep 2020;13:235861.

77. Ferreira JG, Rapparini C, Gomes BM, et al. Pneumothorax as a late complication of COVID-19. Rev Inst Med Trop Sao Paulo 2020;62:e61.

78. Janssen ML, van Manen MJG, Cretier SE, et al. Pneumothorax in patients with prior or current COVID-19 pneumonia. Respir Med Case Rep 2020;31:101187.

79. Chong WH, Saha BK, Hu K, et al. The incidence, clinical characteristics, and outcomes of pneumothorax in hospitalized COVID-19 patients: A systematic review. Heart Lung 2021;50:599-608.

80. Martinelli AW, Ingle T, Newman J, et al. COVID-19 and pneumothorax: a multicentre retrospective case series. Eur Respir J 2020;56:2002697.

81. Chopra A, Al-Tarbsheh AH, Shah NJ, et al. Pneumothorax in critically ill patients with COVID-19 infection: Incidence, clinical characteristics and outcomes in a case control multicenter study. Respir Med 2021;184:106464.

82. Rajdev K, Spanel AJ, McMillan S, et al. Pulmonary Barotrauma in COVID-19 Patients With ARDS on Invasive and Non-Invasive Positive Pressure Ventilation. J Intensive Care Med 2021;8850666211019719.

83. McGuinness G, Zhan C, Rosenberg N, et al. Increased Incidence of Barotrauma in Patients with COVID-19 on Invasive Mechanical Ventilation. Radiology 2020;297:E252-62.

84. Miró Ò, Llorens P, Jiménez S, et al. Frequency, Risk Factors, Clinical Characteristics, and Outcomes of Spontaneous Pneumothorax in Patients With Coronavirus Disease 2019: A Case-Control, Emergency MedicineBased Multicenter Study. Chest 2021;159:1241-55.

85. Wang XH, Duan J, Han X, et al. High incidence and mortality of pneumothorax in critically Ill patients with COVID-19. Heart Lung 2021;50:37-43.

86. Ekanem E, Podder S, Donthi N, et al. Spontaneous pneumothorax: An emerging complication of COVID-19 pneumonia. Heart Lung 2021;50:437-40.

87. Quincho-Lopez A, Quincho-Lopez DL, Hurtado-Medina FD. Case Report: Pneumothorax and Pneumomediastinum as Uncommon Complications of COVID-19 PneumoniaLiterature Review. Am J Trop Med Hyg 2020;103:1170-6.

88. Zantah M, Dominguez Castillo E, Townsend R, et al. Pneumothorax in COVID-19 disease- incidence and clinical characteristics. Respir Res 2020;21:236.

89. Gattinoni L, Coppola S, Cressoni M, et al. COVID-19 Does Not Lead to a "Typical" Acute Respiratory Distress Syndrome. Am J Respir Crit Care Med 2020;201:1299-300.

90. Saha BK, Ghalib S, Chieng H, et al. Correlation of Respiratory Physiologic Parameters in Mechanically Ventilated Coronavirus Disease 2019 Patients. Crit Care Explor 2021;3:e0328.

91. Terzi E, Zarogoulidis K, Kougioumtzi I, et al. Acute respiratory distress syndrome and pneumothorax. J Thorac Dis 2014;6:S435-42.

92. Gattinoni L, Bombino M, Pelosi P, et al. Lung structure and function in different stages of severe adult respiratory distress syndrome. JAMA 1994;271:1772-9.

93. Miller MP, Sagy M. Pressure characteristics of mechanical ventilation and incidence of pneumothorax before and after the implementation of protective lung strategies in the management of pediatric patients with severe ARDS. Chest 2008;134:969-73.

94. Macklin MT, Macklin CC. Malignant interstitial emphysema of the lungs and mediastinum as an important occult complication in many respiratory diseases and other conditions: an interpretation of the clinical literature in the light of laboratory experiment. Medicine (Baltimore) 1944;23:281-58.

95. Shah V, Brill K, Dhingra G, et al. Delayed recurrent spontaneous pneumothorax in a patient recovering from COVID-19 pneumonia. Korean J Anesthesiol 2021;74:183-5.

96. Capleton P, Ricketts W, Lau K, et al. Pneumothorax and Pneumatocoele Formation in a Patient with COVID-19: a Case Report. SN Compr Clin Med 2021;1-4.

97. Akhtar MR, Ricketts W, Fotheringham T. Use of an antiviral filter attached to a pleural drain bottle to prevent aerosol contamination with SARS-CoV-2. Clin Med (Lond) 2020;20:e60-1.

98. Sugimoto H, Kohama T. Chest tube with air leaks is a 
potential "super spreader" of COVID-19. Am J Infect Control 2020;48:969.

99. Li YK, Peng S, Li LQ, et al. Clinical and Transmission Characteristics of Covid-19 - A Retrospective Study of 25 Cases from a Single Thoracic Surgery Department. Curr Med Sci 2020;40:295-300.

100.Duffy C, Kidd A, Francis S, et al. Chest drain aerosol generation in COVID-19 and emission reduction using a simple anti-viral filter. BMJ Open Respir Res 2020;7:e000710.

101.Piro R, Casalini E, Livrieri F, et al. Interventional pulmonology during COVID-19 pandemic: current evidence and future perspectives. J Thorac Dis 2021;13:2495-509.

102. Tsang KW, Ho PL, Ooi GC, et al. A cluster of cases of severe acute respiratory syndrome in Hong Kong. N Engl J Med 2003;348:1977-85.

103. Lee N, Hui D, Wu A, et al. A major outbreak of severe acute respiratory syndrome in Hong Kong. N Engl J Med 2003;348:1986-94.

104. Chan MS, Chan IY, Fung KH, et al. High-resolution CT findings in patients with severe acute respiratory syndrome: a pattern-based approach. AJR Am J Roentgenol 2004;182:49-56.

105.Zhu Z, Lian X, Su X, et al. From SARS and MERS to COVID-19: a brief summary and comparison of severe acute respiratory infections caused by three highly pathogenic human coronaviruses. Respir Res 2020;21:224. 106. Das KM, Lee EY, Langer RD, et al. Middle East

Cite this article as: Saha BK, Chong WH, Austin A, Kathuria R, Datar P, Shkolnik B, Beegle S, Chopra A. Pleural abnormalities in COVID-19: a narrative review. J Thorac Dis 2021;13(7):4484-4499. doi: 10.21037/jtd-21-542
Respiratory Syndrome Coronavirus: What Does a Radiologist Need to Know? AJR Am J Roentgenol 2016;206:1193-201.

107.Das KM, Lee EY, Enani MA, et al. CT correlation with outcomes in 15 patients with acute Middle East respiratory syndrome coronavirus. AJR Am J Roentgenol 2015;204:736-42.

108. Das KM, Lee EY, Al Jawder SE, et al. Acute Middle East Respiratory Syndrome Coronavirus: Temporal Lung Changes Observed on the Chest Radiographs of 55 Patients. AJR Am J Roentgenol 2015;205:W267-74.

109. Geller C, Varbanov M, Duval RE. Human coronaviruses: insights into environmental resistance and its influence on the development of new antiseptic strategies. Viruses 2012;4:3044-68.

110. Kim MC, Kim MY, Lee HJ, et al. CT findings in viral lower respiratory tract infections caused by parainfluenza virus, influenza virus and respiratory syncytial virus. Medicine (Baltimore) 2016;95:e4003.

111. Shiley KT, Van Deerlin VM, Miller WT Jr. Chest CT features of community-acquired respiratory viral infections in adult inpatients with lower respiratory tract infections. J Thorac Imaging 2010;25:68-75.

112. Risk for In-Hospital Complications Associated with COVID-19 and Influenza - Veterans Health Administration, United States, October 1, 2018-May 31, 2020 I MMWR [Internet]. [cited 2021 Jun 3]. Available online: https://www.cdc.gov/mmwr/volumes/69/wr/ mm6942e3.htm 